\title{
White organic light-emitting device based on a compound fluorescent- phosphor-sensitized-fluorescent emission layer
}

\author{
Hiroshi Kanno a) and Yiru Sun \\ Princeton Institute for the Science and Technology of Materials (PRISM), Princeton University, \\ Princeton, New Jersey 08544 and Department of Electrical Engineering, Princeton University, \\ Princeton, New Jersey 08544 \\ Stephen R. Forrest ${ }^{\text {b) }}$ \\ Department of Electrical Engineering and Computer Science, University of Michigan, Ann Arbor, \\ Michigan 48109; Department of Physics, University of Michigan, Ann Arbor, Michigan 48109; \\ and Department of Materials Science and Engineering, University of Michigan, Ann Arbor, \\ Michigan 48109
}

(Received 22 April 2006; accepted 2 August 2006; published online 5 October 2006)

\begin{abstract}
The authors demonstrate a combination fluorescent and phosphor-sensitized-fluorescent white organic light-emitting device (WOLED), employing the conductive host material, 4,4'-bis(9-ethyl-3-carbazovinylene)-1,1'-biphenyl, doped with the phosphorescent green, and the fluorescent red and blue emitters, $f a c$-tris(2-phenylpyridinato- $\left.N, C^{2^{\prime}}\right)$ iridium (III), 4-(dicyanomethylene)-2-t-butyl-6-(1,1,7,7-tetramethyljulolidyl-9-enyl)-4H-pyran, and 4,4'-bis (9-ethy-3-carbazolvinylene)-1-1'-biphenyl, respectively. Although two fluorescent dopants are employed along with only a single phosphor, this simple structure can, in principle, achieve $100 \%$ internal quantum efficiency. In the prototype, the phosphor-sensitized WOLED exhibits total external quantum and power efficiencies of $\eta_{\text {ext,tot }}=13.1 \pm 0.5 \%$ and $\eta_{p, \text { tot }}=20.2 \pm 0.7 \mathrm{~lm} / \mathrm{W}$, respectively, at a luminance of $800 \mathrm{~cd} / \mathrm{m}^{2}$ with Commission Internationale de L'Eclairage chromaticity coordinates of $(x=0.38, y=0.42)$ and a color rendering index of 79. () 2006 American Institute of Physics. [DOI: 10.1063/1.2357038]
\end{abstract}

White organic light-emitting devices (WOLEDs) have gained interest for their use in such applications as flat panel displays and lighting sources. To date, WOLEDs with various configurations combined with suitable materials have been reported to generate the desired white light by doping one or more emission layers (EMLs) with fluorescent or phosphorescent materials. ${ }^{1-5}$ Among these structures, the electrophosphorescent WOLED is one of the most promising routes to high efficiency. ${ }^{1-3}$ More recently, a WOLED consisting of an EML combining a blue fluorophor doped layer and spatially separated red and green phosphor doped layers was demonstrated to have very high luminance and quantum efficiencies. ${ }^{6,7}$ This device, operating on the principle of distribution of all excitons formed in the host to their respective dopants, has the potential for achieving $100 \%$ internal quantum efficiency (IQE), while exhibiting a higher power efficiency than all-phosphor-doped WOLEDs.

An alternative approach reported here simplifies this socalled fluorescent/phosphorescent $(F / P)$ WOLED by replacing two of the three primary color emitting dopants with fluorophors, while still retaining its ability to achieve $100 \%$ IQE. In this device, the red phosphor is exchanged for a red fluorescent dopant whose emission is sensitized by the presence of a codoped phosphor in a common conductive host. ${ }^{8,9}$ By lightly doping the sensitized layer with the red fluorophor, less than complete transfer of triplets from the green phosphor results in a mixture of red and green emissions. Combined with the emission from the spatially separate

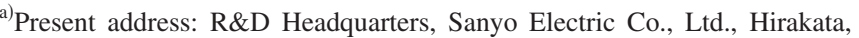
Osaka, Japan.

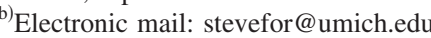

singlet-harvesting blue fluorophor, the desired white color defined here as a color rendering index $(\mathrm{CRI})>80$ is achieved. With this method, a wide variety of fluorescent dyes can be used for WOLEDs. Moreover, this device can maintain the high luminance and quantum efficiencies of the all phosphor and $F / P$ architectures, whereas previously reported phosphor-sensitized WOLEDs (Refs. 10-12) have relatively low efficiencies due to poor energy transfer between dopants.

The compound fluorescent-phosphor-sensitizedfluorescent $(F / P / F)$ WOLED structure is shown in Fig. 1

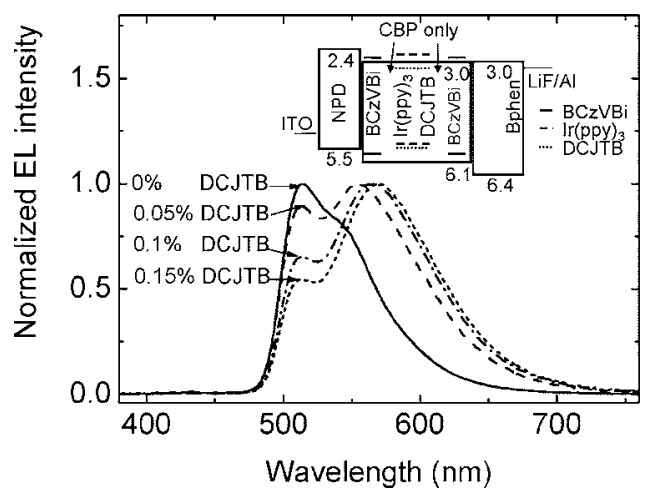

FIG. 1. Electroluminescence spectra at a current density of $J=10 \mathrm{~mA} / \mathrm{cm}^{2}$ as a function of DCJTB concentration doped in CBP with $\operatorname{Ir}(\mathrm{ppy})_{3}$ in the green + red phosphor-sensitized OLED. Inset: Proposed energy level diagram of a compound fluorescent-phosphorescent-sensitized fluorescent white organic light emitting device. Numbers indicate the highest occupied and lowest unoccupied molecular orbital (HOMO and LUMO, respectively) energies relative to vacuum. The corresponding energies of $\mathrm{BCzBVi}$, $\operatorname{Ir}(\mathrm{ppy})_{3}$, and DCJTB are $(\mathrm{HOMO}=5.9 \mathrm{eV}$ and $\mathrm{LUMO}=2.8 \mathrm{eV}),(5.5$ and $2.7 \mathrm{eV})$, and (5.3 and $3.1 \mathrm{eV})$, respectively. 
(inset). The conductive host for both fluorescent and phosphorescent dopants is $4,4^{\prime}-N, N^{\prime}$-dicarbazole-biphenyl (CBP). Two separate blue fluorescent emitting regions are doped with 4,4'-bis(9-ethyl-3-carbazovinylene)$1,1^{\prime}$-biphenyl (BCzVBi), ${ }^{13,14}$ while the phosphor-sensitized zone contains fac-tris(2-phenylpyridinato- $N, C^{2^{\prime}}$ ) iridium(III) $\left(\operatorname{Ir}(\text { ppy })_{3}\right) \quad$ and 4-(dicyanomethylene)-2-t-butyl6-(1,1,7,7-tetramethyljulolidyl-9-enyl)-4H-pyran (DCJTB) codoped in CBP to generate green and red emission, respectively. Exciton formation occurs at the interface between the blue doped regions in the EML, and the 4,7-diphenyl-1,10phenanthroline (Bphen) electron transport and exciton blocking layer (ETL), and at the opposite blue fluorophor-doped EML interface with the hole transport layer (HTL) consisting of 4-4'-bis[ $N$-(1-naphthyl)- $N$-phenyl-amino $]$ biphenyl (NPD). An undoped CBP region forms a spacer between the fluorescent region and a phosphor-doped CBP zone in the center of the EML. The spacer prevents singlet excitons formed on the blue fluorophor from transferring to the lower energy green and red dopants. However, CBP triplets, with their characteristically long diffusion lengths $(>100 \mathrm{~nm})$, migrate into the spatially separated phosphor-doped region. ${ }^{15,16}$

Generally, red emitting dopants act as carrier trapping sites, and consequently the operating voltages of red OLEDs are increased due to the resulting reduced carrier mobility. In the phosphor-sensitized $F / P$ WOLED, the red dopant is only lightly doped at $\sim 0.1 \mathrm{wt} \%$, thereby preventing significant carrier trapping on the fluorophor. Moreover, the power efficiency is increased over that expected for an all-phosphor doped EML by eliminating exchange energy losses incurred by the very high energy required to excite the blue phosphor from both the singlet and triplet states of a fluorescent host.

The $F / P / F$ WOLEDs were grown on glass substrates precoated with 150 -nm-thick, $\sim 20 \Omega /$ sq indium tin oxide (ITO) anode layers. Prior to organic layer deposition, the ITO coating was exposed to a UV+ozone flux for $5 \mathrm{~min}$ following degreasing in detergent solution and solvents. The organic multilayer structure was deposited at a rate of $1-5 \AA / s$ without breaking vacuum, using materials that were previously purified by repeated temperature gradient vacuum sublimation before loading into a vacuum evaporation chamber with a base pressure of $\sim 10^{-7}$ Torr. In one set of OLEDs employing only green and red doped EMLs, a 50-nm-thick NPD layer was grown, followed by a 15-nm-thick green-red EML region consisting of $8 \mathrm{wt} \%$ $\operatorname{Ir}(\mathrm{ppy})_{3}$ codoped with DCJTB at various concentrations in CBP, and then capped by a 30-nm-thick Bphen exciton blocking layer. The dopant concentrations were varied by using a mask with an aperture capable of being translated in vacuum during deposition. The full $F / P / F$ WOLED structure was the same as that used for the green+red OLEDs, except that the symmetric EML consisted of a 10-nm-thick fluorescent blue region (10 wt \% $\mathrm{BCzVBi}$ doped in CBP), a 2-nm-thick undoped CBP spacer, a 15-nm-thick green+red region consisting of $\operatorname{Ir}(\mathrm{ppy})_{3}$ codoped with $0.08 \mathrm{wt} \%$ DCJTB in CBP, a second 2-nm-thick undoped CBP spacer, and a second 10-nm-thick blue fluorescent region. The EML was capped by a 30-nm-thick Bphen layer, as above. Finally, a cathode consisting of $0.8-\mathrm{nm}$-think LiF and 50-nm-thick Al was deposited through a shadow mask with an array of circular, 1.0-mm-diameter openings. Masking for cathode

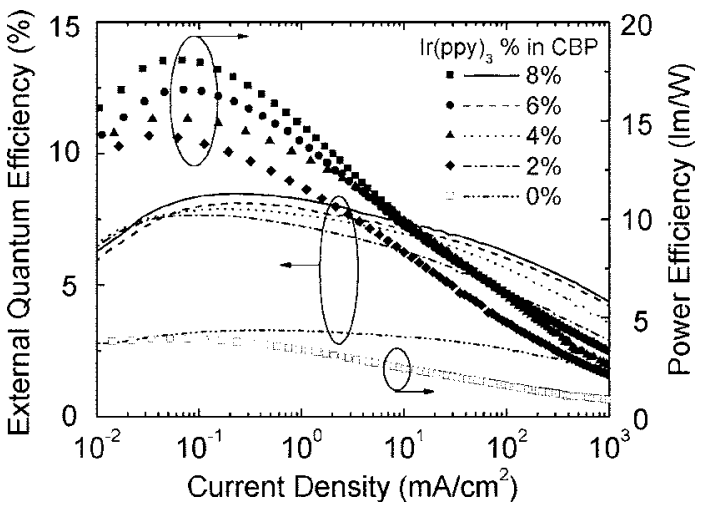

FIG. 2. External (lines) and power (symbols) efficiencies in the forward viewing direction of $F / P / F$ WOLEDs with the following structures: ITO/ NPD $(50 \mathrm{~nm}) / \mathrm{CBP}: 10$ wt $\%$ BCzVBi $(10 \mathrm{~nm}) / \mathrm{CPB}(2 \mathrm{~nm}) / \mathrm{CPB}: x$ wt $\%$ $\operatorname{Ir}(\mathrm{ppy})_{3}: 0.08 \mathrm{wt} \%$ DCJTB $(15 \mathrm{~nm}) / \mathrm{CPB}(2 \mathrm{~nm}) / \mathrm{CBP}: 10 \mathrm{wt} \% \mathrm{BCzVBi}$ $(10 \mathrm{~nm}) /$ Bphen $(30 \mathrm{~nm}) / \mathrm{LiF}(0.8 \mathrm{~nm}) / \mathrm{Al}(50 \mathrm{~nm})$. The $\operatorname{Ir}(\mathrm{ppy})_{3}$ concentration, $x$, was varied as shown.

deposition was completed following organic layer deposition in an ultrahigh purity nitrogen-filled glovebox with $<1 \mathrm{ppm}$ water and oxygen.

Current-voltage and external quantum efficiency measurements were carried out using a semiconductor parameter analyzer (HP 4156C), and a calibrated $\mathrm{Si}$ photodiode (Hamamatsu S3584-08) following standard procedures. ${ }^{17}$

The phosphor-sensitized green + red EML lacking the blue dopants was used to investigate energy transfer as a function of DCJTB concentration. As shown in Fig. 1, the red emission increases with DCJTB concentration. The devices with 0.05 and $0.1 \mathrm{wt} \%$ DCJTB have nearly equal green and red intensities. The peak external quantum efficiencies of these devices are comparable to that of the $\operatorname{Ir}(\mathrm{ppy})_{3}$-only, green phosphorescent device, indicating that significant losses are avoided by sensitization. ${ }^{9}$ At $0.15 \mathrm{wt} \%$ doping of DCJTB, however, the efficiency decreases and the drive voltage at a fixed current is increased. This suggests that at DCJTB concentrations $>0.1 \mathrm{wt} \%$, charge trapping becomes a significant channel for exciton formation, as is typical in purely red-fluorophor-doped OLEDs.

Based on these results, phosphor-sensitized $F / P / F$ WOLEDs were grown with 0.08 wt \% DCJTB, with the $\operatorname{Ir}(\mathrm{ppy})_{3}$ concentration varied from 0 to $8 \mathrm{wt} \%$ in CBP, also including the blue fluorescent doped zones and accompanying spacers at the edges of the EML. The $F / P / F$ WOLED efficiencies and electroluminescence spectra are shown in Figs. 2 and 3, respectively. With increased $\operatorname{Ir}(\mathrm{ppy})_{3}$ concentration from 2 to $8 \mathrm{wt} \%$, the external quantum and power efficiencies increase from $7.6 \pm 0.3 \%(21.9 \pm 0.9 \mathrm{~cd} / \mathrm{A})$ to $8.5 \pm 0.3 \%(22.0 \pm 0.9 \mathrm{~cd} / \mathrm{A})$ and from $14.2 \pm 0.6$ to $18.1 \pm 0.7 \mathrm{~lm} / \mathrm{W}$, respectively. The total external quantum and power efficiencies measured at a surface luminance of $800 \mathrm{~cd} / \mathrm{m}^{2}$ in a $4 \pi$ solid angle for the $8 \mathrm{wt} \% \operatorname{Ir}(\mathrm{ppy})_{3}$ sensitized device are $\eta_{\text {ext,tot }}=13.1 \pm 0.5 \%$ and $\eta_{p \text {,tot }}$ $=20.2 \pm 0.7 \mathrm{~lm} / \mathrm{W}$, respectively. These values are approximately $20 \%$ lower than obtained for the $F / P$ WOLED reported previously, ${ }^{7}$ indicating that there is some excess loss in the phosphor-sensitized fluorescent energy transfer process.

In the absence of the $\operatorname{Ir}(\mathrm{ppy})_{3}$ sensitizer, the forward viewing efficiencies drop sharply to $3.2 \pm 0.2 \%$ and $3.9 \pm 0.2 \mathrm{~lm} / \mathrm{W}$, as expected for a purely fluorescent device. 


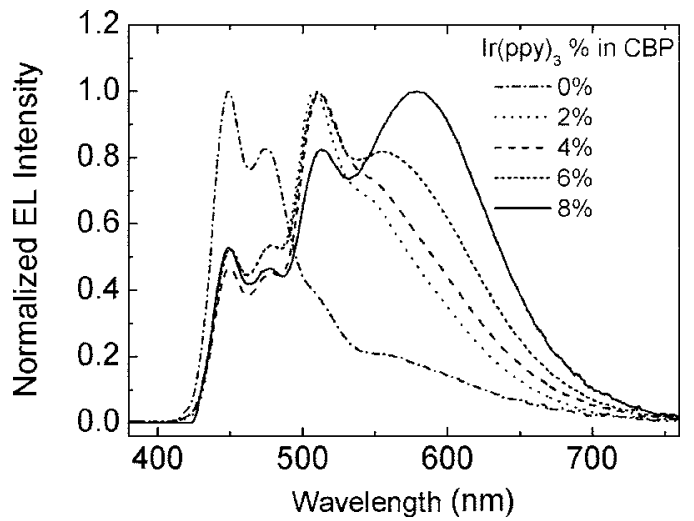

FIG. 3. Electroluminescence spectra of the devices in Fig. 2 at a current density of $J=10 \mathrm{~mA} / \mathrm{cm}^{2}$.

We also find that the red emission from DCJTB increases with increased $\operatorname{Ir}(\mathrm{ppy})_{3}$ concentration (see Fig. 3). Indeed, at $8 \mathrm{wt} \% \operatorname{Ir}(\mathrm{ppy})_{3}$ in CBP, triplet excitons originating in the blue doped zones at the EML edges are effectively transported via diffusion through the CBP spacers, and transferred to the red fluorescent dye by phosphorescent sensitization. The likelihood of direct triplet transfer from the blue dopant to DCJTB, or to $\operatorname{Ir}(\mathrm{ppy})_{3}$, or excitation of these low energy dopants by charge trapping has not been quantified. In comparison with the previously reported $F / P$ device ${ }^{7}$ whose trapping fraction was approximately $25 \%$, that of the $F / P / F$ device is smaller due to the extremely low concentration of the red dopant. Trapping can reduce the overall device efficiency somewhat, although it has been shown by Giebink et $a l^{16}$ that this process can be used to optimally tune the white emission spectrum.

The spectral dependence on current density is shown in Fig. 4. Only slight changes in the spectra are observed from 1 to $100 \mathrm{~mA} / \mathrm{cm}^{2}$, suggesting that balanced carrier injection is a feature of this blocked device structure. The CRIs and Commission Internationale de L'Eclairage coordinates at current densities of 1,10 , and $100 \mathrm{~mA} / \mathrm{cm}^{2}$ are 79 and $(0.39$,

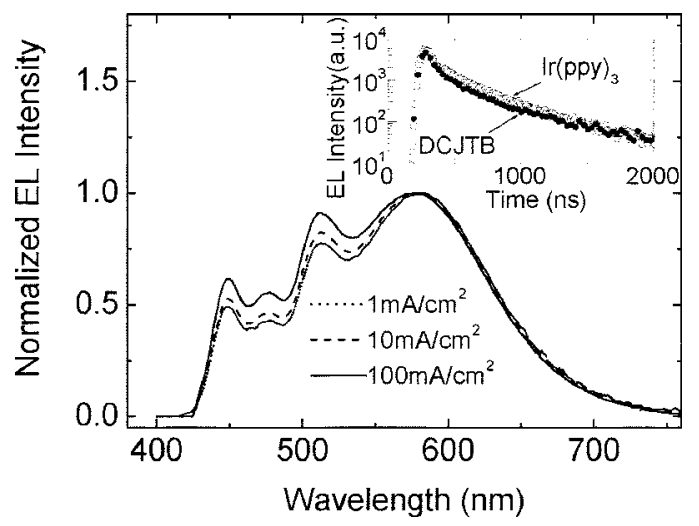

FIG. 4. Electroluminescence spectra of the device with $8 \mathrm{wt} \% \operatorname{Ir}(\mathrm{ppy})_{3}$ doping in CBP in Fig. 2 as a function of current density. Inset: transient electroluminescence response of the DCJTB (closed circles) and $\operatorname{Ir}(\mathrm{ppy})_{3}$ (open circles) spectral components of the device.
$0.42),(0.38,0.42)$, and $(0.37,0.41)$, respectively. The inset of Fig. 4 shows the EL transient decay of the WOLED with 8 wt $\% \operatorname{Ir}(\text { ppy })_{3}$. The response of DCJTB in $\operatorname{Ir}(\text { ppy })_{3}$ as shown in Fig. 4 is identical to that of $\operatorname{Ir}(\mathrm{ppy})_{3}$, much slower than the intrinsic transient lifetime of DCJTB of $\sim 1$ ns. ${ }^{8}$ This suggests that DCJTB is indeed excited via exciton transfer from the phosphor.

In summary, we have demonstrated high efficiency WOLEDs employing a phosphor sensitizer combined with blue and red fluorescent dopants. By changing the relative concentrations of the red fluorophor to the green phosphorescent emitter/sensitizer, we obtain efficient triplet transfer from the blue-doped zones at the edges of the EML to the red-emitting DCJTB, while at the same time harvesting the singlets originating in the CBP host by the blue dopant itself. The WOLEDs have an extended carrier recombination zone, which leads to high external efficiencies at high brightness. The devices reach a maximum forward viewing external efficiency of $\eta_{\mathrm{ext}}=8.5 \pm 0.3 \%$ for the WOLED with $8 \mathrm{wt} \%$ $\operatorname{Ir}(\mathrm{ppy})_{3}$, and a total efficiency of $\eta_{\text {ext,tot }}=13.1 \pm 0.5 \%$ at a luminance of $800 \mathrm{~cd} / \mathrm{m}^{2}$. This corresponds to a total power efficiency of $\eta_{p \text {,tot }}=20.2 \pm 0.7 \mathrm{~lm} / \mathrm{W}$ with a CRI of 79 . These results demonstrate that phosphor-sensitized WOLEDs constitute a simple and efficient route to achieve high brightness and efficient lighting sources while allowing for a broad choice of combinations of fluorescent and phosphorescent dopants.

This work was partially supported by the Department of Energy Solid State Lighting Program via a subcontract from the University of Southern California, and Universal Display Corporation.

${ }^{1}$ B. W. D'Andrade, R. J. Holmes, and S. R. Forrest, Adv. Mater. (Weinheim, Ger.) 16, 624 (2004).

${ }^{2}$ H. Kanno, Y. Sun, and S. R. Forrest, Appl. Phys. Lett. 86, 263502 (2005).

${ }^{3}$ C.-H. Kim and J. Shinar, Appl. Phys. Lett. 80, 2201 (2002).

${ }^{4}$ S. Tokito, T. Iijima, T. Tsuzuki, and F. Sato, Appl. Phys. Lett. 83, 2459 (2003).

${ }^{5}$ Y. Xu, J. Peng, Y. Mo, Q. Hou, and Y. Cao, Appl. Phys. Lett. 86, 163502 (2005).

${ }^{6}$ Y. Sun, N. Giebink, B. Ma, M. E. Thompson, and S. R. Forrest, SPIE Organic Light Emitting Materials and Devices IX, San Diego, 1 August 2005, Paper No. 5937-86.

${ }^{7}$ Y. Sun, N. C. Giebink, H. Kanno, B. Ma, M. E. Thompson, and S. R. Forrest, Nature (London) 440, 908 (2006).

${ }^{8}$ M. A. Baldo, M. E. Thompson, and S. R. Forrest, Nature (London) 403, 750 (2000).

${ }^{9}$ B. W. D'Andrade, M. A. Baldo, C. Adachi, J. Brooks, M. E. Thompson, and S. R. Forrest, Appl. Phys. Lett. 79, 1045 (2001).

${ }^{10}$ G. Cheng, F. Li, Y. Duan, J. Feng, S. Liu, S. Qiu, D. Lin, Y. Ma, and S. T. Lee, Appl. Phys. Lett. 82, 4224 (2003).

${ }^{11}$ G. Lei, L. Wang, and Y. Qiu, Appl. Phys. Lett. 85, 5403 (2004).

${ }^{12}$ Y. Zhang, G. Cheng, Y. Zhao, J. Hou, and S. Liu, Appl. Phys. Lett. 86, 011112 (2005).

${ }^{13}$ K. O. Cheon and J. Shinar, J. Appl. Phys. 81, 1738 (2002).

${ }^{14}$ C. Hosokawa, H. Tokailin, H. Higashi, and T. Kusumoto, J. Appl. Phys. 78, 5831 (1995).

${ }^{15}$ M. A. Baldo and S. R. Forrest, Phys. Rev. B 62, 10967 (2000).

${ }^{16}$ N. C. Giebink, Y. Sun, and S. R. Forrest, Org. Electron. 7, 375 (2006).

${ }^{17}$ S. R. Forrest, D. D. C. Bradley, and M. E. Thompson, Adv. Mater. (Weinheim, Ger.) 15, 1043 (2003). 